\title{
O ensino de PLE para fins específicos e a produção de livros didáticos
}

\author{
André Gonçalves Ramos \\ Universidade Federal de Santa Maria \\ goncalvesramos.andre@gmail.com \\ Maria Tereza Nunes Marchesan \\ Universidade Federal de Santa Maria \\ ttmarchesan@gmail.com
}

\begin{abstract}
Resumo
O ensino de português como língua estrangeira (PLE) para fins específicos é um campo ainda pouco explorado na área da Linguística Aplicada, apesar de um grande interesse pela investigação do processo de ensino-aprendizagem em contextos específicos. Considerando essa lacuna, este trabalho tem como objetivo contribuir para a identificação da dimensão adquirida pela área de PLE para fins específicos no Brasil Buscamos, com isso, encontrar uma relação entre a falta de materiais didáticos e o incipiente desenvolvimento da pesquisa nesse âmbito. Para tanto, destacamos a questão da interação entre aluno e material didático e sua importância para a construção do processo de aprendizagem de línguas estrangeiras. Em seguida, traçamos um histórico sobre a produção de livros didáticos de PLE para fins gerais e para fins específicos. Concluímos apresentando um retrato atual da pesquisa na área de PLE para fins específicos e sua relação com a falta de livros didáticos nessa área.
\end{abstract}

Palavras-chave: Português para fins específicos; livro didático; interação.

\begin{abstract}
The teaching of Portuguese for Specific Purposes is a new area in Applied Linguistics despite the great interest in the teaching and learning processes in specific contexts. Therefore, this paper aims at discussing the relationship between few teaching materials and the incipient development of research in this area. Hence, it starts by presenting a discussion about the interaction between student and teaching material and highlighting its importance to the foreign language learning process. Then it considers the production of
\end{abstract}


Portuguese for general and specific purposes textbooks. The article concludes by presenting the current picture of research in Portuguese for specific purposes and its relation to the lack of textbooks in this area.

Keywords: Portuguese for specific purposes, teaching material, interaction.

\section{Introdução}

A área de ensino de português como língua estrangeira (PLE) tem crescido no Brasil. Apesar disso, há muito que se fazer para que essa área alcance padrões desejáveis de desenvolvimento. Almeida Filho (2007) apresenta uma avaliação do estado atual e do progresso do ensino de PLE, recorrendo a índices específicos de desenvolvimento, e conclui que o Brasil apresenta um desempenho apenas mediano.

Os dados apresentados por Almeida Filho (2007) revelam que há iniciativas para a consolidação da área em todos os critérios arrolados pelo autor como necessários para a avaliação. $\mathrm{O}$ índice geral de 4.14 numa escala que vai até 10 , no entanto, evidencia, segundo o autor (2007, p. 47) a necessidade de uma política linguística mais consistente, principalmente, para a criação de estratégias para o ensino de língua portuguesa e da cultura brasileira para falantes estrangeiros, tanto no país quanto no exterior.

Almeida Filho (2007) também apresenta um quadro ilustrativo das pesquisas concluídas no âmbito de PLE em programas de pósgraduação brasileiros. Nesse quadro, destaca-se um maior número de pesquisas centradas na área de processos de aquisição. Ao analisar o quadro, é possível notar que - apesar de um grande interesse pela investigação do processo de ensino-aprendizagem em contextos específicos, voltados, em sua maioria, para "atender as necessidades de descrição, explicação e fundamentação do processo de ensinar e aprender" (ALMEIDA FILHO, 2007, p. 51) - não há trabalhos que abordem o ensino de PLE para fins específicos.

Apesar existir um grande interesse pela investigação do processo de ensino-aprendizagem em contextos específicos, é possível afirmar que o ensino de PLE para fins específicos é um campo ainda pouco explorado na área da Linguística Aplicada. No entanto, não há trabalhos que deem conta do estado atual dessa área no Brasil. Dessa 
forma, visando a contribuir para a identificação da dimensão adquirida pela área de PLE para fins específicos, este trabalho apresenta um histórico da produção de livros didáticos para o ensino/aprendizagem de PLE,buscando encontrar uma relação entre a falta de produção de materiais didáticos e o incipiente desenvolvimento da pesquisa nesse âmbito. Para tanto, iniciamos destacando a questão da interação entre aluno e material didático e sua importância para a construção do processo de aprendizagem de línguas estrangeiras. Em seguida, apresentamos um breve histórico sobre a produção de livros didáticos de PLE para fins gerais e para fins específicos. O trabalho é finalizado com uma discussão sobre um retrato atual da pesquisa na área de PLE para fins específicos e sua relação com a falta de livros didáticos nessa área.

\section{Interação aluno-material didático}

Há atualmente um consenso teórico e empírico sobre a importância da interação no conhecimento e na aprendizagem, que tem origem nos estudos sobre o desenvolvimento empreendidos na área da psicologia (PÁUCAR; VALENCIA, 2009). Nesse sentido, o descobrimento e a grande repercussão, na área da Educação ocidental, do conceito de Zona de Desenvolvimento Proximal (ZDP) proposto pelo psicólogo bielo-russo Lev Vygotsky, na década de 1920, fez com que a aprendizagem por meio da interação tivesse grande volume de pesquisas e de aplicações durante a segunda metade do século XX e início do XXI. O conceito de ZDP refere-se ao nível de desenvolvimento mental de cada indivíduo. Segundo Vygotsky (1998), pode-se medir a capacidade mental tomando o desenvolvimento realisto é, levando em conta tudo o que conseguimos fazer sem ajuda de terceiros- ou considerando o desenvolvimento potencial- isto é, levando em conta tudo o que somos capazes de realizar com a ajuda de alguém mais experiente. Dessa forma, a ZPD é uma área psicológica que se forma entre o nível de desenvolvimento real e o nível de desenvolvimento potencial. Ela é um indicativo das funções que ainda não amadureceram, mas que já estão em processo de se tornar funções consolidadas. Assim, à medida que se avança no desenvolvimento, ou seja, à medida que as funções potenciais se tornam capacidades reais, 
novas funções passam a fazer parte da ZDP renovando-a constantemente (VYGOTSKY, 1998).

No entanto, é preciso considerar que, apesar de estarem diretamente ligados, o fluxo do desenvolvimento e o fluxo da aprendizagem transcorrem separadamente. Para Vygotsky (idem, p. 118), "o processo de desenvolvimento progride de forma mais lenta e atrás do processo de aprendizado". É desse anacronismo que surge a zona de desenvolvimento proximal. A partir desse conceito, entende-se que a interação, no processo ensino/aprendizagem, é capaz de atuar diretamente na zona potencial do aluno, proporcionando resultados satisfatórios de desenvolvimento intelectual.

Atualmente, há considerável número de produções sobre a interação no processo ensino/aprendizagem de língua estrangeira (LE), abordando ou não o conceito de ZDP. Nessa área, encontramos primordialmente trabalhos que enfocam a interação aluno-professor e/ou a interação aluno-aluno (ABRAHÃO, 1992; GARCEZ, 2006; FERREIRA, 2008; GREGÓRIO, 2007; KALANTARI, 2009; SEEDHOUSE, 2005; TAVARES, 2006).

Tendo em vista a ampla discussão que se estabeleceu em torno dos estudos sobre a interação professor-aluno e aluno-aluno na sala de aula de línguas, enfocamos aqui a interação aluno-conteúdo e a implicação desse tipo de interação para a produção de material de aprendizagem.

A interação aluno-conteúdo é descrito por Moore (1989, p. 1) como "processo de interação intelectual com o conteúdo que resulta em mudanças no entendimento, na perspectiva ou nas estruturas cognitivas do aprendiz"1. O autor sustenta que esse é o tipo de interação que envolve uma conversação didática interna, quando o aluno fala para si sobre a informação e sobre a ideia que encontra em um texto ou outro material.

Segundo Moore e Kearsley (1996), citados em Woods e Baker (2004, p. 3),

\footnotetext{
${ }^{1}$ Tradução nossa para:"the process of intellectually interacting with content that results in changes in the learner's understanding, the learner's perspective, or the cognitive structures of the learner's mind".
} 
Cada aluno tem de construir conhecimento através de um processo pessoal de acomodação de informação em estruturas cognitivas previamente existentes. É a interação com o conteúdo que resulta em mudanças na compreensão do aluno ${ }^{2}$ (MOORE; KEARSLEY, 1996, apud WOODS; BAKER, 2004, p. 3).

Considerando-se que para haver aprendizagem e desenvolvimento cognitivo é preciso uma interação entre o conhecimento prévio e conhecimento novo- entre capacidades já adquiridas e aquelas que estão em processo de amadurecimento na zona de desenvolvimento proximal (VYGOTSKY, 1998) - a interação entre o aluno e o conteúdo torna-se imprescindível no processo de aprendizagem. No dizer de Moore (1989), sem a interação alunoconteúdo não pode haver educação. Então, retomando o conceito de ZDP, podemos considerar que não é, unicamente, a interação com pessoas mais experientes que garante o andamento dos processos de aprendizagem e desenvolvimento, mas também, e necessariamente, a interação entre o aprendiz e o novo conteúdo a ser interiorizado e amadurecido cognitivamente.

Os trabalhos que discutem a interação aluno-conteúdo, segundo Thurmond e Wambach (2004), quase sempre estão ligados aoutros tipos de interação, como a interação aluno-professor, alunoaluno oualuno-interface. Além disso, percebemos que grande parte desses estudos está inserida quase que exclusivamente no contexto de ensino a distância (MOORE, 1989; PAIVA, 2003; WOODS; BAKER, 2004; THURMOND; WAMBACH, 2004).

Refletindo sobre os resultados desses trabalhos, sob o ponto de vista dos materiais didáticos, vislumbramos a necessidade de se considerar a interação entre aluno e o conteúdo como algo de grande importância, que precisa ser levada em conta na hora de analisar, planejar, produzir e avaliar MDs.

\footnotetext{
${ }^{2}$ Tradução nossa para: "Every learner has to construct knowledge through a process of personally accommodating information into previously existing cognitive structures. It is interacting with content that results in these changes in the learner's understanding".
} 
O conceito de enunciado como unidade da comunicação discursiva proposto por Bakhtin (2010) fornece elementos teóricos que sustentam a existência de uma interação entre o MD e o aluno. Do ponto de vista do interlocutor, todo enunciado, oral ou escrito, provoca uma atitude responsiva no seu interlocutor.Nas palavras do autor,

(...) ao perceber e compreender o significado (linguístico) do discurso, (o ouvinte) ocupa simultaneamente em relação a ele uma ativa posição responsiva: concorda ou discorda dele (total ou parcialmente), completa-o, aplica-o, preparase para usá-lo, etc. (...) Toda compreensão da fala viva, do enunciado vivo é de natureza ativamente responsiva (embora o grau desse ativismo seja bastante diverso); toda compreensão é prenhe de resposta, e nessa ou naquela forma a gera obrigatoriamente: o ouvinte se torna falante (BAKHTIN, 2010, p. 271).

Bakhtin (2010, p. 272) considera ainda que os enunciados que não suscitam respostas aparentes imediatas também comportam componente responsivo, uma vez que a resposta pode se configurar como uma "compreensão responsiva de efeito retardado". Assim, cedo ou tarde, o interlocutor dará uma resposta por meio dos discursos subsequentes ou do próprio comportamento. Do ponto de vista do enunciador, devemos considerar que ele está determinado à compreensão responsiva de seu interlocutor, isto é, ao produzir seu discurso, ele não espera um entendimento passivo sobre o que disse, mas sim considera as possíveis respostas ativamente responsivas, uma participação, uma concordância, um questionamento, enfim, uma interação de fato.

Se transportarmos essa realidade para a interação entre o elaborador de MDs e o aluno, concordaremos com o fato de que o primeiro precisa conhecer bem o seu interlocutor (o aluno), suas necessidades, preferências, sua abordagem de aprender, seu conhecimento prévio, etc, para poder oferecer um discurso (material didático) que propicie a atitude ativamente responsiva esperada. Nesse caso, a atitude responsiva esperada refere-se à compreensão e ao amadurecimento de novos conhecimentos. Para isto, é claro, a atitude responsiva do aluno deve se dar em zona de desenvolvimento proximal, isto é, a resposta provocada pelo discurso (MD) deve ser o 
desenvolvimento de capacidades que estavam em estado potencial e que passam para o estágio de desenvolvimento real a partir da interação com o enunciado.

Considerando o suporte escrito, predominante nos MDs, concordamos com a definição de leitura apresentada por Pinto e Cavichioli (2005, p. 1) de que "a leitura deve ser a atividade por meio da qual o leitor tem como interagir com o autor por meio do texto escrito". Esse conceito expressa uma perspectiva sociointeracionista da leitura, na qual o processo de interação resulta das práticas sociais estabelecidas. O aluno constrói, então, seus significados na medida em que a interação ocorre, permitindo, segundo as autoras, "a construção e a sustentação dialética da sua identidade na L2" (PINTO; CAVICHIOLI, 2005, p. 1).

É preciso destacar que esse processo não é exclusivo do ensino a distância e, portanto, deve ser levado em conta na hora de considerar o MD para ensino presencial também.

\section{Livro didático de PLE}

Entre os diferentes materiais didáticos que são passiveis de serem usados no processo ensino-aprendizagem de línguas, destaca-se o livro didático (LD). Segundo Pacheco (2006. p. 62-63), esse destaque é merecido porque "o LD é imprescindível às atividades de ensino/aprendizagem em inúmeros espaços e em diferentes tempos em que esse processo tem-se desenvolvido". A autora (2006) cita uma série de pesquisadores que convergem sobre a importância do LD na sala de aula(CORACINI,1999; PEREIRA, 2000; ALMEIDA FILHO, 2002; SOUZA, 1999; ORLANDI, 1998; TICKS, 2005), considerandoo "imprescindível", na medida em que, muitas vezes, ele é o "único mediador no ensino promovido pela instituição-escola" (PACHECO, 2006, p. 64).

No que diz respeito ao LD no ensino de PLE, de acordo com Lopes (2009, p. 136), a determinação deste "exige uma análise aprofundada para que os objetivos traçados no programa do curso sejam atingidos com satisfação pelo professor e pelos alunos". Pacheco (2006), por sua vez, destaca outros aspectos importantes a serem considerados acerca dos LDs: 
[...] as suas funções econômica e político-pedagógica e a sua incontestável inserção na política educacional, o seu papel nas políticas editorial e pública; a sua legitimidade no meio educacional, o que lhe atribui um poder de 'enformação' muito grande, na corrente do discurso da competência, tendo em vista as 'verdades' sacramentadas que ele permite sejam transmitidas e partilhadas (PACHECO, 2006, p. 64).

Nesse sentido, ainda segundo Pacheco (2006), o LD goza de um status de prestígio no Brasil desde muito tempo antes da fundação da primeira escola pública brasileira, o Colégio Pedro II. No entanto, foi no cenário educacional montado a partir da sua fundação, no início do século XIX, que se originou um contexto filosófico que teve no LD um papel importante de legitimação do saber, pois ele passou a ser, de fato, a fonte autorizada de transmissão dos saberes acumulados na sociedade.

No entanto, no que se refere aos LDs de PLE, não se pode ter o mesmo entendimento sobre seu status, uma vez que os esforços oficiais voltaram-se para a melhoria da qualidade dos materiais de ensino de português língua materna (PLM) (PACHECO, 2006). Na verdade, foram os imigrantes que, por muito tempo, impulsionaram a produção e uso de LDs de PLE no Brasil na primeira metade do século XX. Segundo Pacheco (2006),

Aproveitando-se da obrigatoriedade imposta de escolaridade mínima de cinco anos (a partir de 1920), foram organizadas associações de professores, jornal do professor, cursos para professores e dado amplo incentivo à produção de MDs (PACHECO, 2006, p. 70).

No Rio Grande do Sul, por exemplo, foram produzidos mais de 150 manuais didáticos para uso específico da escola teuto-brasileira (KREUTZ, 2003, apud PACHECO, 2006). Da mesma forma, outros grupos de imigrantes como os italianos, poloneses e japoneses - seja por compreensão da importância do aprendizado do português para a comunidade, seja por obrigação imposta pela legislação nacional - 
também desenvolveram LDs para aplicá-los em suas escolas (PACHECO, 2006).

A partir da década de 1930, porém, o governo brasileiro intensificou o processo de "nacionalização" dos imigrantes, impondo o ensino de português para estrangeiros, baseado em metodologias de ensino de língua materna. Isso foi possível graças à criação de escolas públicas junto às escolas de imigrantes, o que inviabilizou o funcionamento destas (PACHECO, 2006). Além disso, houve outras medidas que visavam à "homogeneização" do ensino de português no território brasileiro, como, por exemplo, a proibição de ensino de língua estrangeira a menores de 14 anos; a obrigatoriedade de todos os membros do corpo docente das escolas serem brasileiros natos; a proibição da circulação de textos, livros, jornais ou revistas em língua estrangeira; a destruição de MDs estrangeiros, etc. (PACHECO, 2006).

Assim, criou-se, até a década de 1950, uma situação de escassez de MDs de PLE no Brasil. Os poucos cursos de PLE que se mantiveram durante essa fase utilizavam material vindos do exterior, principalmente dos Estados Unidos (PACHECO, 2006). Foi, então, a partir desse período, que os professores brasileiros de PLE iniciaram um processo de criação de MDs.

De acordo com Morita (1998), o primeiro LD brasileiro foi publicado em 1950, produzido por Mercedes Marchant, da Pontifícia Universidade Católica do Rio Grande do Sul (PUC-RS). Esse material refletia uma preocupação com a oralidade, ainda que, seguindo os preceitos da época, fosse baseado somente nos elementos da frase. Em 1954, surge Português para Estrangeiros, desenvolvido por professores e linguistas brasileiros, porém baseados em modelos de MDs importados do exterior (PACHECO, 2006).

Nos anos 60, formou-se uma equipe binacional (norteamericana e brasileira) que elaborou uma edição experimental do famoso manual Modern Portuguese (PACHECO, 2006). Nas décadas de 1960 e 1970, outros MDs de base estruturalista foram publicados em diferentes países (LOPES, 2009). No Brasil, nessa mesma época, houve uma abertura para a educação bilíngue e para o ensino de PLE decorrente, principalmente, da abertura da economia nacional ao mercado externo (PACHECO, 2006). Segundo Pacheco (2006), 
Muitos executivos passaram a vir do exterior para assumirem os cargos de direção das empresas multinacionais que no país se instalavam, especialmente no sudeste do país. Além disso, convênios foram firmados, e alguns grandes projetos 'multinacionais', como a construção da usina nuclear de Angra dos Reis, foram também responsáveis pela vinda de técnicos especializados estrangeiros, que imigravam acompanhados de suas famílias e matriculavam seus filhos em escolas internacionais, existentes no Rio e em outros estados da federação. Esses novos alunos passavam a frequentar aulas de PLE, como forma de acelerar seu processo de adaptação ao país (PACHECO, 2006, p. 73).

Dessa forma, o início do desenvolvimento do Brasil como uma força econômica na América Latina impulsionou o desenvolvimento de cursos de PLE, e essa demanda originou, de certa forma, a necessidade de construção de conhecimento nessa área.

A partir da década de 1980, e mais sistematicamente, na década de 1990, houve um significativo avanço da literatura na área de PLE, impulsionado pela institucionalização dessa área nas universidades brasileiras. Esses fatores, por sua vez, alavancaram as produções de MDs didáticos de PLE nacionais. Vislumbra-se, nos anos 2000, um aumento de produções e de propostas mais inovadoras, relacionadas às necessidades do mercado (LOPES, 2009). Lopes (2009) apresenta um gráfico ilustrativo do aumento da produção de LD de PLE no Brasil:

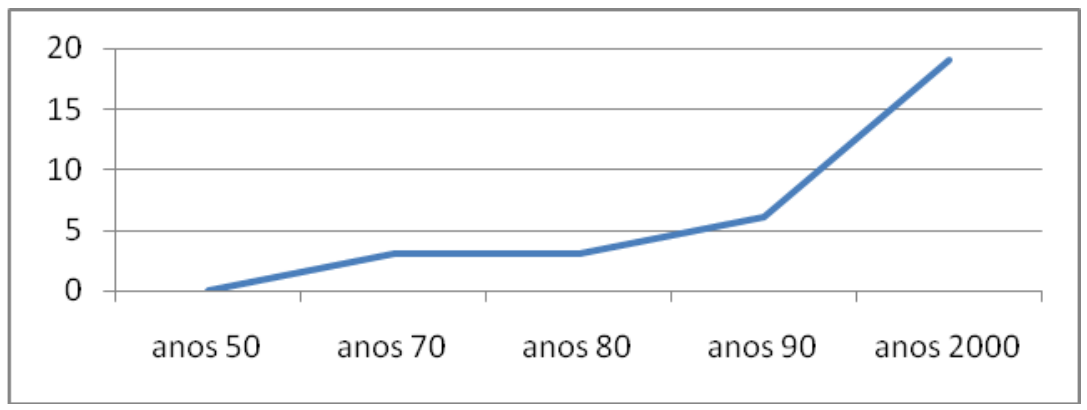

Figura 1 - Crescimento da produção de livros didáticos de PLE no Brasil (LOPES, 2009, p. 139) 
Outra maneira de vislumbrar o desenvolvimento da produção de LDs de PLE no Brasil é acompanhando esse processo por meio da linha cronológica de produção. Pacheco (2006) apresenta o histórico de produção de LDs de PLE no Brasil:

Quadro 1. Cronologia da produção de LDs em PLE (PACHECO, 2006, p. 81-84)

\section{Cronologia da produção de LDs em PLE}

1901 - Manual de língua portuguesa, Rudolf Damm.

1954 - Português para estrangeiros, $1^{\circ}$ Livro, Mercedes Marchant, Porto Alegre: Sulina.

1973 - Português: conversação e gramática. Haydée Magro e Paulo de Paula. São Paulo: Brazilian American Cultural Institute / Livraria Pioneira Editora.

1974 - Português para estrangeiros, $2^{\circ}$ Livro, Mercedes Marchant, Porto Alegre: Sulina.

1978-Português do Brasil para estrangeiros. Vol. 1. S. Biazoli e Francisco G. Matos. São Paulo: Difusão Nacional do Livro.

1978 - Português para estrangeiros I e II: conversação cultura e criatividade. S. Biazoli e Francisco G. Matos. São Paulo: Difusão Nacional do Livro Editora e Importadora Ltda.

1978 - Português do Brasil para estrangeiros Vol. 2. S. Biazoli e Francisco G. Matos. São Paulo: Difusão Nacional do Livro.

1980 - Falando, lendo, escrevendo português: um curso para estrangeiros, Emma Eberlein O. F. Lima e Samira A. Iunes, São Paulo: Ed. EPU (Editora Pedagógica e Universitária).

1983 - Português para falantes de espanhol. Leonor Cantareiro Lombello e Marisa de Andrade Baleeiro. Campinas, SP: UNICAMP/FUNCAMP/MEC.

1984 - Tudo bem 1: português do Brasil, Raquel Ramalhete, Rio de Janeiro: Ed. Ao Livro Técnico S/A, Indústria e Comércio.

1985 - Tudo bem 2: português do Brasil, Raquel Ramalhete, Rio de Janeiro, Ed. Ao Livro Técnico S/A.

1989 - Fala Brasil: português para estrangeiros, Elizabeth Fontão do Patrocínio e Pierre Coudry, São Paulo, Campinas, Pontes Editores Ltda.

1989 - Muito Prazer! Curso de português do Brasil para estrangeiros. Ana Maria Flores. Volumes I e II. Rio de Janeiro: Ed. Agir.33 


\section{Cronologia da produção de LDs em PLE}

1990 - Português via Brasil: um curso avançado para estrangeiros, Emma Eberlein O. F. Lima, Lutz Rohrman, Tokiko Ishihara, Cristián Gonzalez Bergweiler e Samira A. Iunes. São Paulo: Ed. EPU.

1990 - Português como segunda língua. Almeida, M. e Guimarães, L. Rio de Janeiro: Ao Livro Técnico.

1991 - Avenida Brasil 1: curso básico de português para estrangeiros, Emma Eberlein O.F. Lima, Lutz Rohrmann,Tokiko Ishihara, Cristián González Bergweiler e Samira Abirad Iunes. São Paulo: Ed. EPU.

1992 - Aprendendo português do Brasil, Maria Nazaré de Carvalho Laroca, Nadine Bara e Sonia Maria da Cunha. Campinas, São Paulo: Pontes Editores Ltda.

1994 - Português para estrangeiros: infanto-juvenil. Mercedes Marchand. Porto Alegre: Age.

1995 - Avenida Brasil II - Emma E. Lima, Cristián Gonzaléz e Tokiko Ishihara. São Paulo: EPU.

1997 - Português para estrangeiros: nível avançado. Mercedes Marchand. Porto Alegre: Age.

1998 - Português para estrangeiros I e II. MEYER, R. M et alii. Rio de Janeiro: PUCRio. (Edição experimental).

1999 - Falar, ler e escrever português: um curso para estrangeiros (reelaboração de Falando, lendo, escrevendo português) de Emma E. O.F. Lima e Samira A I. São Paulo: Ed. EPU.

1999 - Bem-vindo! Maria Harumi Otuki de Ponce; Silvia R.B. Andrade Burin e Susanna Florissi. São Paulo, Editora SBS.

2000 - Sempre amigos: fala Brasil para jovens. Elizabeth Fontão do Patrocínio e Pierre Coudry. Campinas, SP: Pontes.

2000 - Sempre amigos: de professor para professor. Elizabeth Fontão do Patrocínio e Pierre Coudry. Campinas, SP: Pontes.

2001 - Tudo bem? português para nova geração. Volume 2. Maria Harumi Otuki de Ponce, Silvia Regina. B. Andrade Burim e Susana Florissi. São Paulo: Ed. SBS.

2001 - Interagindo em português. Eunice Ribeiro Henriques e Danielle Marcelle Granier. Brasília: Thesaurus.

2002 - Passagens: português do Brasil para estrangeiros com Guia de respostas sugeridas. Rosine Celli. Campinas, SP: Pontes.

2003 - Diálogo Brasil: curso intensivo de português para estrangeiros. Emma Eberlein O. F. Lima, Samira Abirad Iunes e Marina Ribeiro Leite. São Paulo: Ed. EPU. 


\section{Cronologia da produção de LDs em PLE}

2004 - Aquarela do Brasil: curso de português para falantes de espanhol. Edileise Mendes Oliveira Santos (MD proposto em sua Tese de Doutoramento, apresentada na UNICAMP, em 2004).

2005 - Estação Brasil: português para estrangeiros. BIZON, A C. Campinas, SP: Ed. Átomo.

Analisando as datas de publicação, podemos afirmar que a cronologia da produção de LDs de PLE, apresentada por Pacheco (2006), converge com o gráfico de Lopes (2009), mostrando um grande aumento a partir da década de 1990.

Não obstante o grande aumento na produção de LDs de PLE, se comparada com a situação dos LDs de PLM, ainda é possível levantar diversos pontos que precisam ser aprimorados. Segundo Morita (1998, p. 65), os LDs de PLE “ainda estão longe de competir com a qualidade de apresentação dos livros de inglês, francês e mesmos de português como língua materna". Entretanto, Lopes (2009, p. 138) projeta um avanço eminente, considerando a "progressão da visibilidade internacional do Brasil". Dessa forma, espera-se que o aumento da demanda gere - como tem gerado historicamente - um aumento na qualidade de produção, tanto de materiais teóricos, quanto práticos nessa área.

Almeida Filho (2007) apresenta índices nacionais de desenvolvimento de PLE, estabelecendo um sistema de critérios para essa tarefa e destacando um quadro "alentador, embora longe de plenamente satisfatório ao nível de preparo para o ensino institucionalizado e profissional de PLE que reconhecemos como necessário para a nossa época" (ALMEIDA FILHO, 2007, p. 51). A produção científica merece destaque nesse quadro positivo da área de PLE.

Pacheco (2006) destaca que, no contexto atual, enquanto o inglês se apresenta como língua universal, o português e o espanhol vêm ganhando espaço em virtude da criação do Mercosul, desde a década de 1990. Almeida Filho (2007) também afirma que a língua espanhola ganhou muito destaque no Brasil devido ao advento do Mercosul e assevera que há provisões cada vez mais visíveis para o ensino de PLE em países membros desse bloco. 
Os atuais avanços atestam que o ensino de PLE vai se recolocando em lugar de destaque dentro desse novo contexto.Pacheco (2006) elenca uma série de frentes de trabalho que têm sido abertas no Brasil ultimamente.A seguir, apresentamos um resumo dessas atividades, de acordo com Pacheco (2006, p. 74-78):

1. formação de centros de referência de PLE nas universidades brasileiras, na década de 1990;

2. a criação do exame de certificação de proficiência para estrangeiros, o CELPE-Bras;

3. a produção acadêmica em centros de referência em PLE no Brasil como, por exemplo, o Programa de Estudos PósGraduados em Linguística Aplicada e Estudos da Linguagem (LAEL) e o Núcleo de Pesquisa Português Língua Estrangeira (NUPPLE) do Instituto de Pesquisa Sedes Sapientiae (IP) da Pontifícia Universidade Católica de São Paulo (PUC - SP) e o Instituto de Estudos da Linguagem (IEL) da UNICAMP;

4. a oferta de licenciatura Português do Brasil Segunda Língua, na UnB, desde 1998;

5. a criação, em 1992, da Sociedade Internacional de Português Língua Estrangeira;

6. a abertura de espaço para a área de PLE em grandes congressos de Linguística e Linguística Aplicada; e

7. a promoção de eventos científico-acadêmicos específicos da área de PLE.

A seu turno, Almeida Filho (2007) também revela algumas ações que se destacam no desenvolvimento da área de PLE. Entre elas estão: bolsas fornecidas pela CAPES e CNPq por meio do PEC-PG para alunos de países conveniados; o Exame Nacional de Proficiência CELPE-BRAS em expansão gradual; a realização de eventos (congressos, encontros e grupos de trabalho) e a existência de uma associação de professores de PLE (SIPLE). Acrescentamos a essas atividades o Programa de Qualificação Docente e Ensino de Língua Portuguesa (PQLP/CAPES/UFSC), que objetiva a formação em Língua Portuguesa Instrumental, de professores de diferentes níveis de ensino em Timor-Leste.

Diante disso, não há dúvidas sobre o fato de estarmos vivenciando uma nova etapa no processo de institucionalização do 
ensino de PLE. No entanto, é preciso considerar que ainda há muitos desafios no campo da produção de MDs de PLE. Para Lopes (2009, p. 151), esses desafios apontam, principalmente, "para a necessidade de uma maior variedade de tipos de materiais para que os professores possam fazer opção de acordo com as necessidades e a realidade de seus alunos". Na área da pesquisa em PLE, destacamos o juízo de Pacheco (2006), sobre a necessidade de investigações como fruto do trabalho em conjunto entre docentes e pesquisadores em perspectiva interdisciplinar.

\section{Livro didático de PLE para fins específicos}

Considerando o mercado de LDs de PLE, hoje, no Brasil, há uma maior produção com foco geral para jovens e adultos. No entanto, essa característica é insuficiente para atender a uma demanda que se apresenta cada vez mais específica. De acordo com Morita (1998), é urgente a necessidade de produção de materiais mais específicos. Para a autora, precisamos de materiais que focalizem separadamente as quatro habilidades linguísticas/comunicativas: produção oral, compreensão auditiva, leitura e escrita em PLE (MORITA, 1998). No entanto, colocamo-nos mais de acordo com Kelm (2004), que afirma que o desafio maior é conseguir combinar, em cursos de línguas instrumentais, tarefas de desempenho específico (performancetasks) com tarefas de linguagem (languagetasks) correspondentes. Precisamos de materiais que realmente enfoquem tarefas específicas de diferentes áreas do mundo profissional e acadêmico sob o ponto de vista da língua estrangeira que esta ou aquela atividade demanda. Um exemplo de produção desse tipo são os materiais de PLE para agentes da polícia rodoviária do Uruguai e os materiais de ELE (espanhol língua estrangeira) para policiais rodoviários brasileiros (países que recebem anualmente milhares de turistas "vizinhos" que os acessam por via terrestre) elaborados pela Universidade Federal de Santa Maria (UFSM), por meio do Centro de Ensino e Pesquisa de Línguas Estrangeiras Instrumentais (CEPESLI). No entanto, esses materiais ainda não estão disponíveis no mercado de livros brasileiro.

Além de foco mais específico, outra característica que deve ser considerada na hora de elaborar MDs para fins específicos e que 
certamente ajudará a alcançar os objetivos e superar os desafios que se colocam atualmente para esta área é oestímulo ao desenvolvimento da autonomia do aluno. Segundo Marchesan (2012), cursos de curta duração, caráter intensivo e a necessidade de formar um aluno autônomo são características do ensino para fins específicos. Assim, considerando a impossibilidade de se ensinar, em cursos de línguas, tudo o que os alunos necessitam, Nunan (1992) sugere que os objetivos de ensino de LE devam estar relacionados ao desenvolvimento de estratégias de aprendizagem. Destaca-se, portanto, que a autonomia do aluno deve ser uma das metas durante a elaboração e/ou seleção de MDs para ensino de PLEpara fins específicos.

No entanto, ainda há falta de materiais específicos na área de PLE no mercado brasileiro. Lopes (2009) afirma que, de todos os LDs de PLE encontrados em sua pesquisa (dezessete no total), somente quatro apresentam uma abordagem específica. Nesse sentido, se observarmos os títulos dos livros na cronologia de elaboração de MDs apresentada por Pacheco (2006), notaremos que apenas sete dos trinta e um títulos apresentados contém algum tipo de especificação. Apesar disso, a maioria deles apresenta uma indicação ainda bastante ampla, e nenhuma obra destina-se para o ensino de PLE para fins profissionais ou acadêmicos; são, na verdade, indicações de foco em determinadas habilidades (Português: conversação e gramática; Português para estrangeiros I e II: conversação cultura e criatividade) ou indicações de público-alvo (Português para falantes de espanhol; Português para estrangeiros: infanto-juvenil; Sempre Amigos: Fala Brasil para Jovens; Tudo Bem? Português para Nova Geração; Aquarela do Brasil: Curso de Português para falantes de espanhol).

Considerando essa situação, a tarefa de análise e seleção de MDs de PLE para fins específicos torna-se extremamente limitada. Os professores que assumem o desafio de produzir e ministrar cursos de PLE para os mais diversos fins descobrem o imperativo da produção de todo o MD a aplicar. Por outro lado, aqueles que se dedicam a esta tarefa baseando-se em pressupostos teóricos da área de línguas instrumentais, geralmente acabam se beneficiando, pois muitas vezes seus materiais atendem de forma mais próxima às necessidades de aprendizagem de seus alunos e, consequentemente, aos objetivos do curso. Além disso, segundo Cunningsworth (1995, apud LOPES, 2009, p. 144), os LDs com fins específicos per se apresentam vantagens 
frente aos livros gerais, "afinal eles foram desenvolvidos especialmente para os alunos com necessidades específicas que não podem ser contempladas pelos livros didáticos para cursos gerais".

\section{Pesquisa em PLE para fins específicos}

No campo da pesquisa, apesar da expansão de publicações especializadas na área de PLE (ALMEIDA FILHO, 2007; PACHECO, 2006), poucas produções têm tratado das especificidades do ensino de PLE para fins específicos. Essa situação fica ainda mais evidente se comparada com a abundância de produções envolvendo o ensino de inglês para fins específicos (English for Specific Purposes).

Analisando as comunicações apresentadas no II Congresso Nacional de Línguas para Fins Específicos (LinFE), realizado em São Paulo no ano de 2012, é possível verificar que a grande maioria dos trabalhos se dedica à língua inglesa. Dos 155 trabalhos apresentados no evento, 110 se referem a ela. O espanhol, com 16 apresentações no total, foi a segunda língua mais tratada em trabalhos. Em seguida, vêm o francês e o português LM, com oito apresentações cada uma. Há ainda trabalhos que integraram mais de uma língua, sendo que uma delas sempre era o inglês. Assim, foram três trabalhos enfocando inglês e PLM e doi que trataram do inglês e do espanhol concomitantemente. O PLE foi representado por apenas um trabalho ${ }^{3}$, da mesma forma que o alemão e o italiano. Outros cinco trabalhos não se enquadraram em nenhuma das classificações por língua, pois apresentavam foco em outros campos relacionados com a área de línguas para fins específicos como, por exemplo, a história da abordagem instrumental, a leitura em aulas de línguas com fins específicos e aspectos teóricos da Análise de Necessidades.

O Quadro 2 apresenta a relação entre os trabalhos apresentados e as diferentes línguas enfocadas.

${ }^{3}$ Língua, Fronteira e Ensino de Português como Língua Estrangeira. Autores: André Gonçalves Ramos e Maria Tereza Nunes Marchesan. 
O ensino de PLE para fins específicos...

Quadro 2. Relação trabalhos/língua nas comunicações no II LinFE, 2012

\begin{tabular}{|l|c|c|}
\hline \multicolumn{1}{|c|}{ LÍNGUA } & $\mathbf{N}^{\mathbf{0}}$ DE TRABALHOS & \% \\
\hline Inglês & 110 & 70,96 \\
\hline Espanhol & 16 & 10,32 \\
\hline Francês & 08 & 5,16 \\
\hline Português LM & 08 & 5,16 \\
\hline Inglês/Português LM & 03 & 1,93 \\
\hline Inglês/Espanhol & 02 & 1,29 \\
\hline Alemão & 01 & 0,64 \\
\hline Italiano & 01 & 0,64 \\
\hline Português LE & 01 & 0,64 \\
\hline Outros & 05 & 3,22 \\
\hline TOTAL & $\mathbf{1 5 5}$ & $\mathbf{1 0 0}$ \\
\hline
\end{tabular}

Pode-se perceber que, da mesma forma que há poucos livros didáticos disponíveis no mercado, poucos são os trabalhos de pesquisa que estão focando o ensino de PLE para fins específicos. A pouco expressiva marca de $0,64 \%$ de trabalhos apresentados no mais importante evento de línguas para fins específicos do Brasil ilustra um descompasso entre o crescimento da área de PLE para fins gerais em relação à área de PLE para fins específicos. Podemos, dessa forma, entrever uma relação mais ou menos direta entre o estado atual da pesquisa em PLE para fins específicos e o fato de faltar materiais mais específicos no mercado editorial de PLE no Brasil.

\section{Considerações finais}

Verificamos, neste trabalho, o papel da interação entre aluno e material didático para a construção da aprendizagem de LE e a consequente importância do livro didático para processo de ensino/aprendizagem. Além disso, foi possível perceber que a produção de materiais para o ensino de PLE vem aumentando nas últimas décadas, porém, no que tange a livros de PLE para fins específicos esse aumento não se verifica com a mesma intensidade. A falta de MDs próprios para grupos específicos de profissionais e/ou acadêmicos encontra ressonância na escassez de pesquisas na área de PLE para fins específicos. Em termos gerais, isso nos leva a afirmar 
que apesar do crescimento da área de PLE no Brasil, este não é proporcional ao crescimento da área de PLE para fins específicos.

Por fim, diante do exposto podemos asseverar que há no Brasil um vasto campo a ser explorado no que diz respeito à pesquisa e à produção de materiais didáticos de PLE para fins específicos. O incremento da produção de LDs de PLE para fins específicos virá à medida que mais trabalhos de pesquisa nessa área forem desenvolvidos no país.

\section{Referências}

ABRAHÃO, Maria. H. V. Um estudo da interação aluno-aluno em atividades em pares ou em grupos na aula de língua estrangeira. 1992. Dissertação. 472f. (Mestrado em Linguística Aplicada) - Instituto de Estudos da Linguagem. Campinas: UNICAMP, 1992.

ALMEIDA FILHO, José. C. P. Português e espanhol nas relações de interface no Mercosul. Em Aberto. ano 15, n.68, p. 45-48, 1995.

. Índices nacionais de desenvolvimento do ensino de português

língua estrangeira. In: ALMEIDA FILHO, José. C. P.; CUNHA, Maria. J. C (Orgs.). Projetos iniciais em português para falantes de outras línguas. Campinas, SP: Pontes, 2007.

BAKHTIN, Mikhail. Estética da criação verbal. Tradução de Paulo Bezerra. 5. ed. São Paulo: MartinsFontes, 2010.

CARVALHO, Ana. M. Estudo de atitudes lingüísticas sobre português de hispano-falantes: até que ponto o portunhol é aceitavel? In. WIEDWMANN, Lyris; SCARAMUCCI, Matilde V. R. (Orgs.) Português para falantes de espanhol:ensino e aquisição. Campinas: Pontes, 2008.

FERREIRA, Marília. M. Constraints to peer scaffolding. Trabalhos de Linguística Aplicada, v. 47, n. 1, p. 9-29, 2008. 
O ensino de PLE para fins específicos...

GARCEZ, Pedro. A organização da fala-em-interação na sala de aula: controle social, reprodução de conhecimento, construção conjunta de conhecimento. Calidoscópio, v. 4, n. 1, p. 66-80, 2006.

GREGÓRIO Regina M. Formação de professores e interação em sala de aula In: CONGRESSO LATINO-AMERICANO SOBRE FORMAÇÃO DE PROFESSORES DE LÍNGUAS, 1., 2006, Florianópolis. Anais... Florianópolis: UFSC, 2007. p. 448-494.

KALANTARI, Reza. Techniques for classroom interaction. International Journal of Language Studies, v. 3, n.4, p. 425-434, 2009.

LOPES, José H. Materiais didáticos de português para falantes de outras línguas: do levantamento de produções brasileiras a uma nova proposta. In. FURTOSO, Viviane. B. Formação de professores de português para falantes de outras línguas: reflexões e contribuições. Londrina: EDUEL, 2009.

MARCHESAN, Maria T. N. Considerações sobre o ensino instrumental de PLE e ELE para policiais. In. STURZA, Eliana R.; et al. (Orgs.). Português e espanhol: esboços, percepções e entremeios. Santa Maria: PPGL, 2012.

MOORE, Michael. G. Three types of interaction. American Journal of Distance Education, v. 3, n. 2, p. 1-7, 1989.

MORITA, Marisa K. (Re)Pensando sobre o material didático de PLE. In. SILVEIRA, Regina. C. (Org.) Português língua estrangeira: perspectivas. São Paulo: Cortez, p. 59-72, 1998.

NUNAN, David. The learner-centred curriculum. Cambridge: Cambridge University Press, 1992.

PACHECO, Denise. G. L. C. Português para estrangeiros e os materiais didáticos: um olhar discursivo. 2006. 335f. Tese (Doutorado em Letras) - Instituto de Letras, UFRJ, Rio de Janeiro, 2006. 
PAIVA, Vera L. M. O. Feedback em ambiente virtual. In: LEFFA, Vilson J. (Org.). Interação na aprendizagem das línguas. Pelotas: Educat, p. 219-254, 2003.

PAUCAR, Marco Antonio; VALENCIA, Sergio. M. Modelos de estudio de la interacción didáctica en la sala de clase. Investigación y Postgrado, v. 24, n. 2, p. 61-76, 2009.

PINTO, Cândida M.; CAVICHIOLI, Fabrícia. O design de uma unidade de curso para o ensino de português como segunda língua. Revista Linguagem e Cidadania. 14 ed. Dez, 2005.

SEEDHOUSE, Paul. Classroom interaction: possibilities and impossibilities. ELT Journal, v.50, n. 1, p. 16-24, 1996.

TAVARES Roseanne R. Estratégias de negociação da imagem em sala de aula de língua estrangeira. In: LEFFA, Vilson J. (Org.). A interação na aprendizagem de línguas. 2 ed. Pelotas: Educat, 2006.

THURMOND, Veronica; WAMBACH, Karen. Understanding interactions in distance education: a review of the literature. International Journal of Instructional Technology and Distance Learning, v. 1. n. 1, 2004.

VYGOTSKY, Lev. A formação social da mente: o desenvolvimento dos processos psicológicos superiores. Tradução. José Cipolla Neto; Luís Silveira Menna Barreto; Solange Castro Afeche. 6 ed. São Paulo: Martins Fontes, 1998.

WOODS, Robert; BAKER, Jason. Interaction and immediacy in online learning. The International Review of Research in Open and Distance Learning, v.. 5, 2004.

Submetido em: 06/09/2013 Aceito em: 24/10/2014

Title: Portuguese for Specific Purposes and the production of teaching materials 